\title{
Recent Progress on Thermo-electrical Properties of Conductive Polymer Composites and Their Application in Temperature
}

\section{Sensors}

\author{
Jianwen Chen, ${ }^{1,2}$ Yutian Zhu, ${ }^{1,{ }^{*}}$ Zhanhu Guo ${ }^{3,{ }^{*}}$ and Albert G. Nasibulin ${ }^{4,5}$
}

\section{Abstract}

Upon heating, the inner conductive pathway inside the conductive polymer composites (CPCS) changes, thus causing the change in electrical resistance. This thermo-electrical dependence of CPCS can be utilized to design CPCs-based temperature sensors. Herein, we systematically review the recent progress on CPCs-based temperature sensors, as well as their mechanisms and applications in different fields. Finally, the question and challenge of CPCs-based temperature sensors are also discussed.

Keywords: Conductive Polymer Composites; Thermo-electrical Properties; Temperature Sensor; Positive Temperature Coefficient; Negative Temperature Coefficient.

Received: 9 June 2020; Accepted: 2 August 2020.

Article type: Review article.

\section{Introduction}

Introducing electrically conductive fillers or components into an insulated polymer matrix can fabricate the conductive polymer composites (CPCs), which makes the insulated polymer materials electrically conductive ${ }^{[1-3]}$ Compared to metals, CPCs possess a lot of advantages, such as light weight, resistance to corrosion, good processing properties, low-cost, and so on. In general, the carbonaceous nanoparticles (e.g. carbon black (CB), ${ }^{[4-16]}$ carbon fibers (CFs), ${ }^{[17-24]}$ single-walled carbon nanotubes (SWCNTs), ${ }^{[25-29]}$ multi-walled carbon nanotubes (MWCNTs), ${ }^{[1,30-39]}$ graphene (GE), ${ }^{[40-49]}$ and graphite nanosheets, ${ }^{[50-55]}$ and metal conducting polymers ${ }^{[62-67]}$ are used as the conductive fillers to fill into polymer matrix to

\footnotetext{
${ }^{1}$ College of Materials, Chemistry and Engineering, Hangzhou Normal University, No. 2318 Yuhangtang Rd., Cangqian, Yuhang District, Hangzhou, 311121, China.

${ }^{2}$ State Key Laboratory of Polymer Physics and Chemistry, Changchun Institute of Applied Chemistry, Chinese Academy of Sciences, Changchun 130022, China.

${ }^{3}$ Integrated Composites Laboratory (ICL), Department of Chemical \& Biomolecular Engineering, University of Tennessee, Knoxville, TN 37996, USA.

${ }^{4}$ Skolkovo Institute of Science and Technology, Nobel str. 3, 143026, Moscow, Russia.

${ }^{5}$ Aalto University, P. O. Box 16100, 00076 Aalto, Finland.

*E-mail: ytzhu@hznu.edu.cn (Y. T. Zhu); zguo10@utk.edu (Z. Guo).
}

fabricate the CPCs. Among these conductive fillers, the carbonaceous nanoparticles are the most common fillers since they possess both high electrical conductivity and good processability with the polymer matrix. As the conductive fillers are introduced into the polymer matrix, there is normally a critical concentration of the fillers, which can achieve an insulator/conductor transition for the CPCs. This critical concentration is defined as the conductive percolation threshold $\left(\rho_{c}\right)$ based on the classic percolation theory. For $\rho>\rho_{c}, \quad \rho_{c}$ can be determined by Equation (1):[68]

$$
\sigma \propto\left(\rho-\rho_{c}\right)^{t}
$$

where $\rho$ is the concentration of conductive filler, $\rho_{c}$ is the conductive percolation threshold, $\sigma$ is the electrical conductivity of the composites, and $t$ is a critical exponent dominated by the dimension of the conductive network in the composites. In other words, $\rho_{c}$ can be regarded as the lowest concentration of the conductive fillers to build up a percolated conductive pathway within the insulated polymer matrix.

Since the electrical properties of CPCs are highly dependent on the conductive pathway inside the matrix, a slight change in the conductive pathway may result in a remarkable change in the output electrical signals (currents or resistances) of the CPCs. Based on this principle, CPCs can be designed into various promising sensors, including strain sensor, ${ }^{[57,69-79]}$ pressure sensor, ${ }^{[80-91]}$ temperature sensor, ${ }^{[92-104]}$ and solvent sensor ${ }^{[19,105-114]}$ to monitor the 
external stimuli, such as strain, pressure, temperature, solvent, and so on. Until now, there are already some published review articles, ${ }^{[115-120]}$ which mainly focus on the electrical properties of CPCs and their applications as strain/pressure sensors. For example, $\mathrm{Li}$ and coworkers ${ }^{[116]}$ systematically reviewed the dependence of the electrical properties of CPCs on the filler type, host polymer, dispersion and phase structure of the composites. Recently, we summarized the advances of strain sensors based on flexible CPCs. ${ }^{[118]}$ In that review article, the sensing mechanisms of different types' strain sensors as well as the influence factors to the sensing properties were discussed. Up to now, however, there are still no specialized review articles that focus on the temperature sensors based on the CPCs. In the current review article, we systematically review the mechanisms of CPCs-based temperature sensors as well as their progress on temperature sensors.

\section{Sensing mechanisms of CPCs-based temperature sensors}

For the filling-type CPCs, the conductive fillers are randomly filled into the polymer matrix, the current or resistance changes with the increase of temperature, which is called thermoelectric phenomenon. Based on this characteristic, the filling-type CPCs can be utilized to design sensors to monitor the temperature. The intrinsic nature of the thermo-electrical dependence is the change of the electrically conductive pathway formed by the fillers as the temperature is changed. When the CPCs are heated, the expansion of the host polymer will cause the destruction of the conductive pathway inside the polymer matrix, thus resulting in an increase in the resistance of CPCs. The increase of resistance of CPCs with temperature is defined as the positive temperature coefficient (PTC) effect. ${ }^{[121,122]}$ PTC effect is a universal phenomenon of CPCs. Since the increase of resistance is mainly caused by the expansion of the host polymer during heating, the coefficient of thermal expansion of the polymer matrix plays a critical role in the PTC effect of CPCs. ${ }^{[123,124]}$ For example, Rybak et al. ${ }^{[124]}$ filled silver (Ag) nanoparticles into different polymer matrixes and compared their PTC effects. They observed that high-density polyethylene (HDPE)/Ag composites exhibited the most significant PTC effect. The resistivity was increased by more than 10 orders of the magnitude as the temperature was increased from 25 to $75^{\circ} \mathrm{C}$. On the contrary, there was almost no PTC effect for the poly (m-xylene adipamide) (MXD6)/Ag composites because of the low thermal expansion of the MXD6 matrix.

When the temperature is higher than melting temperature $\left(T_{m}\right)$ of the crystalline polymer matrix or glass transition temperature $\left(T_{g}\right)$ of the amorphous polymer matrix, however, the resistance of the $\mathrm{CPCs}$ is normally decreased with increasing the temperature, which is attributed to the reconstitution of the conductive network. The phenomenon that the resistivity decreases with increasing the temperature is defined as the negative temperature coefficient (NTC) effect. ${ }^{[125,126]}$ For most of CPCs composed of randomly dispersed conductive fillers and polymer hosts, the NTC effect is always accompanied by PTC effect upon heating. ${ }^{[127-129]}$ This non-monotonic resistance-temperature dependence causes the common CPCs hard to be designed into the temperature sensors. To generate CPCs with monotonic PTC or NTC effect, it needs to design more complex conductive structures instead of random conductive networks inside the polymer matrix. For example, it was found in our previous work that the foamed CPCs exhibited an almost linear NTC effect of resistance upon heating. ${ }^{[130]}$ In that work, we fabricated the $\mathrm{CB} /$ chlorinated poly(propylene carbonate) (CPPC) foam and cross-linked CPPC phase. During the heating (Fig. 1), the gas expansion induced the thinning of foam walls, thereby caused a decrease in the distance between the $\mathrm{CB}$ particles. As a result, the resistance of the $\mathrm{CB} / \mathrm{CPPC}$ foams was decreased upon heating. In the subsequent cooling process, gas shrinking caused the recovery of the cross-linked CPPC walls to their initial state, thus resulting in the increase of resistance.

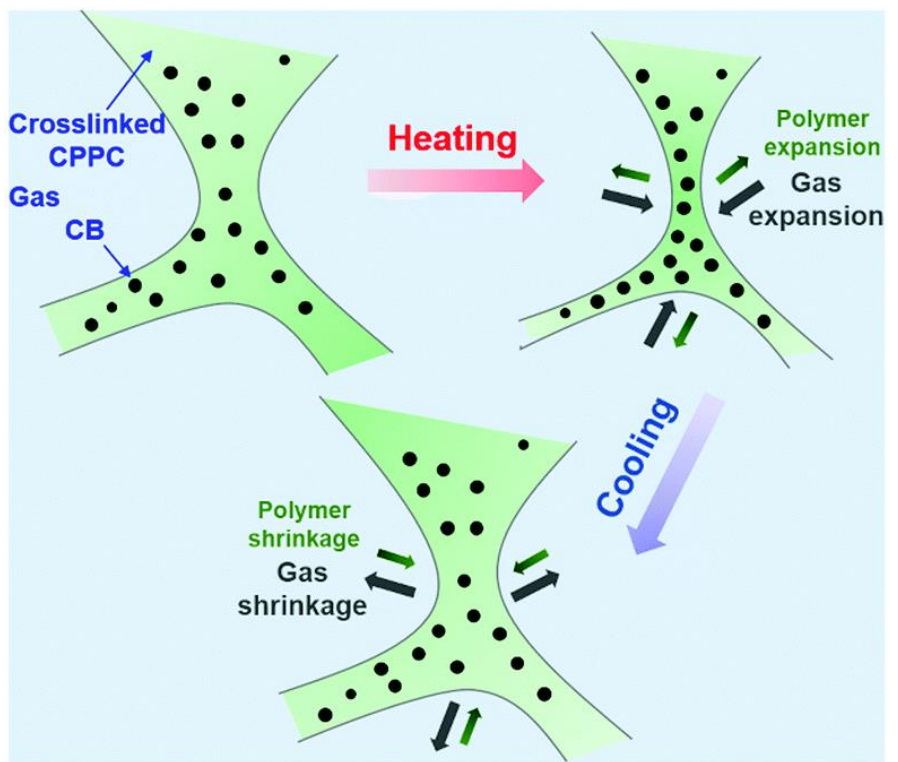

Fig. 1 Schematic illustration of inner structure of crosslinked $\mathrm{CB} / \mathrm{CPPC}$ foams during a heating-cooling cycle. Reprinted with permission from Ref. 130. Copyright (2018) Royal Society of Chemistry.

Another strategy to fabricate the temperature sensor is to embed the thermistor materials, normally the conductive nanoparticles or polymers, inside the flexible polymer substrate. ${ }^{[131-133]}$ This strategy is often used to combine with other sensors (strain or pressure sensors) to fabricate the multifunctional sensors. For instance, Bae et al. ${ }^{[132]}$ used the reduced graphene oxide (RGO) as the temperature sensor and combined it with the flexible capacitive pressure sensor to fabricate the pressure/temperature multifunctional sensors, as shown in Fig. 2(a). Moreover, Hong et al. ${ }^{[133]}$ prepared a resistor-type temperature sensing film (layer $4,1 \times 1 \mathrm{~cm}^{2}$ ) by embedding the conductive polyaniline nanofibers in the polydimethylsiloxane (PDMS) substrates, which was used to fabricate the stretchable temperature sensors (Fig. 2(b)). 

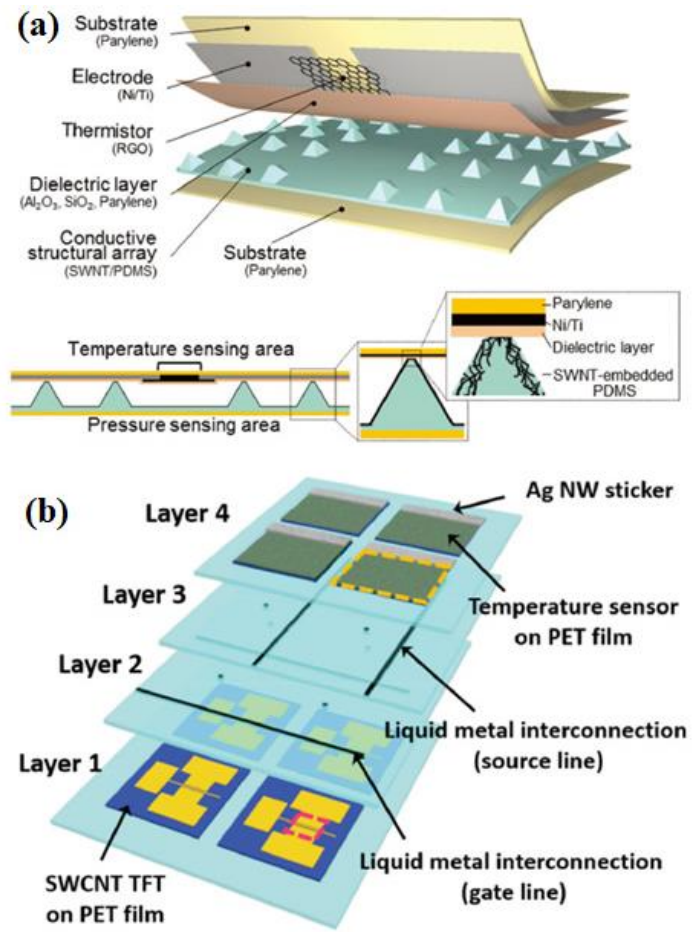

Fig. 2 (a) Schematic illustration of a multifunctional sensor composed of spray-coated RGO thermistor as the temperature sensor and the conductive truncated pyramidal layer as the pressure sensor. Reprinted with permission from Ref. 132. Copyright (2018) Wiley-VCH. (b) Schematic illustration of the structure of a stretchable temperature sensor embedded with a resistor-type temperature sensing film. Reprinted with permission from Ref. 133. Copyright (2016) Wiley-VCH.

\section{Application of CPCs-based temperature sensors}

Based on the thermal expansion of the polymer matrix, the conductive network inside the host polymer will be destroyed, thus causing the increase of resistance of CPCs upon heating (i.e. PTC effect). Although the PTC effect is a universal phenomenon during the heating of $\mathrm{CPCs}$, it is hard to be directly utilized to design into temperature sensors. First, the resistance of CPCs always exhibits a nonlinear increase with increasing the temperature. Second, it is observed that the NTC effect accompanies with the PTC effect, which makes a non-monotonic resistance-temperature dependence of CPCs. Those deficiencies limit the practical applications of traditional CPCs in the temperature sensors. In our previous work, we fabricated the crosslinked $\mathrm{CB} / \mathrm{CPPC}$ foams and utilized them to design the temperature sensors. Attributed to the gas expansion-induced thinning of cell walls, the foamed $\mathrm{CB} / \mathrm{CPPC}$ composites show the linear NTC effect of resistance with increasing temperature from 25 to $70^{\circ} \mathrm{C}$, as shown in Fig. 3(b). From the demonstration experiment shown in Fig. 3(a-c), it is clearly observed that the connected LED lamp becomes brighter and brighter as the temperature is increased from 25 to $70{ }^{\circ} \mathrm{C}$ because of the NTC effect of crosslinked $\mathrm{CB} / \mathrm{CPPC}$ foams. Moreover, the crosslinked $\mathrm{CB} / \mathrm{CPPC}$ foams exhibit good reproducibility of the NTC effect by the recovery of the cell during cooling, which can be observed in the heating-cooling cycles (Fig.4 (d)). Besides the foamed structure of CPCs, some other structures were also utilized to fabricate polymer-based NTC thermistors. For example, Zhao et al. ${ }^{[134]}$ designed the segregated and doublepercolated structure to inhibit the polymer volume expansion effect, while graphene nanosheets construct a conductive network simultaneously, which obtained the NTC temperature sensing materials.

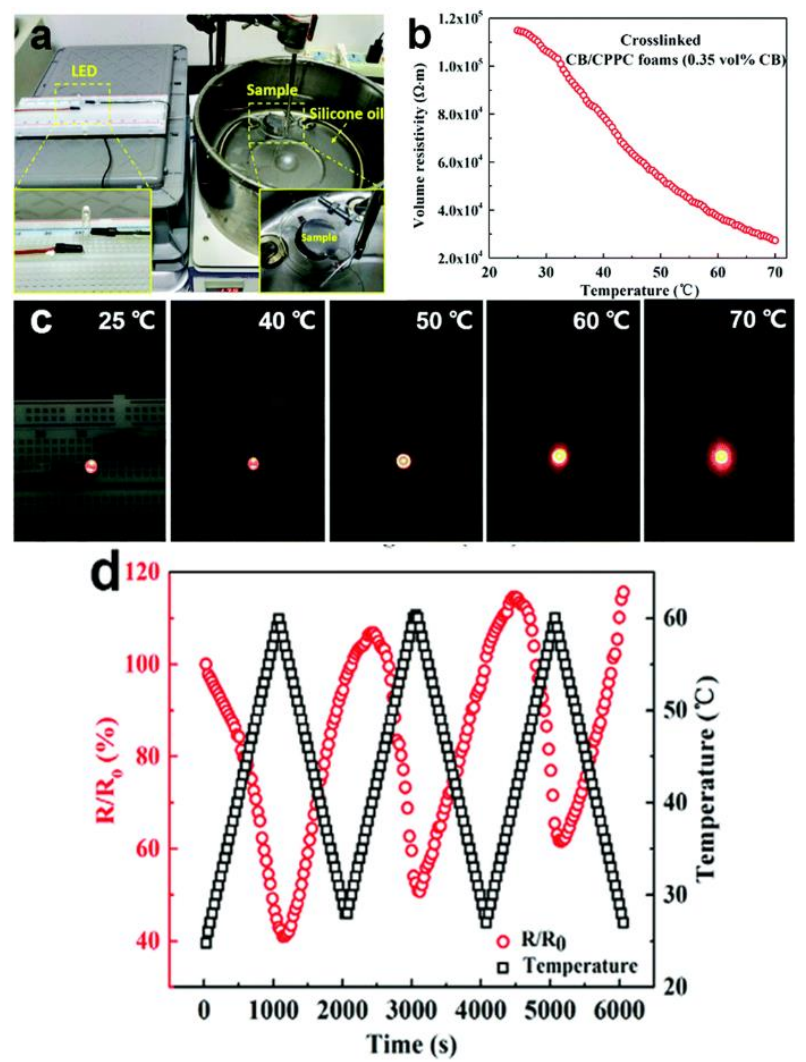

Fig. 3 (a) A simple circuit connected a LED lamp with a crosslinked CB/CPPC foam $(0.35$ vol\% CB) (in an oil bath). (b) Dependence of the resistance of the crosslinked CB/CPPC foam on temperature. (c) The brightness of the LED lamp is enhanced as heating the crosslinked CB/CPPC foam from $25^{\circ} \mathrm{C}$ to $70{ }^{\circ} \mathrm{C}$. (d) The dependence of the resistance of the crosslinked CB/CPPC foam on time in heating-cooling cycles from room temperature to $60{ }^{\circ} \mathrm{C}$. Reprinted with permission from Ref. 130. Copyright (2018) Royal Society of Chemistry.

As we have described above, another effective strategy for the fabrication of polymer-based temperature sensor is to encapsulate a prefabricated temperature sensing layer between the flexible substrates. The encapsulated temperature sensing layer is normally composed of some conductive components, such as inorganic conductive nanoparticles and conductive polymers, which exhibit a thermoelectric behavior. For instance, Oh et al. ${ }^{[135]}$ fabricated a temperature sensing layer containing a composite of poly(N-isopropylacrylamide) (pNIPAM)-temperature sensitive hydrogel, $\operatorname{poly}(3,4-$ ethylenedioxythiophene) polystyrene sulfonate, and carbon nanotubes (CNTs), which is encapsulated between two PDMS thin films to assemble into a high-sensitive and skin-attachable 

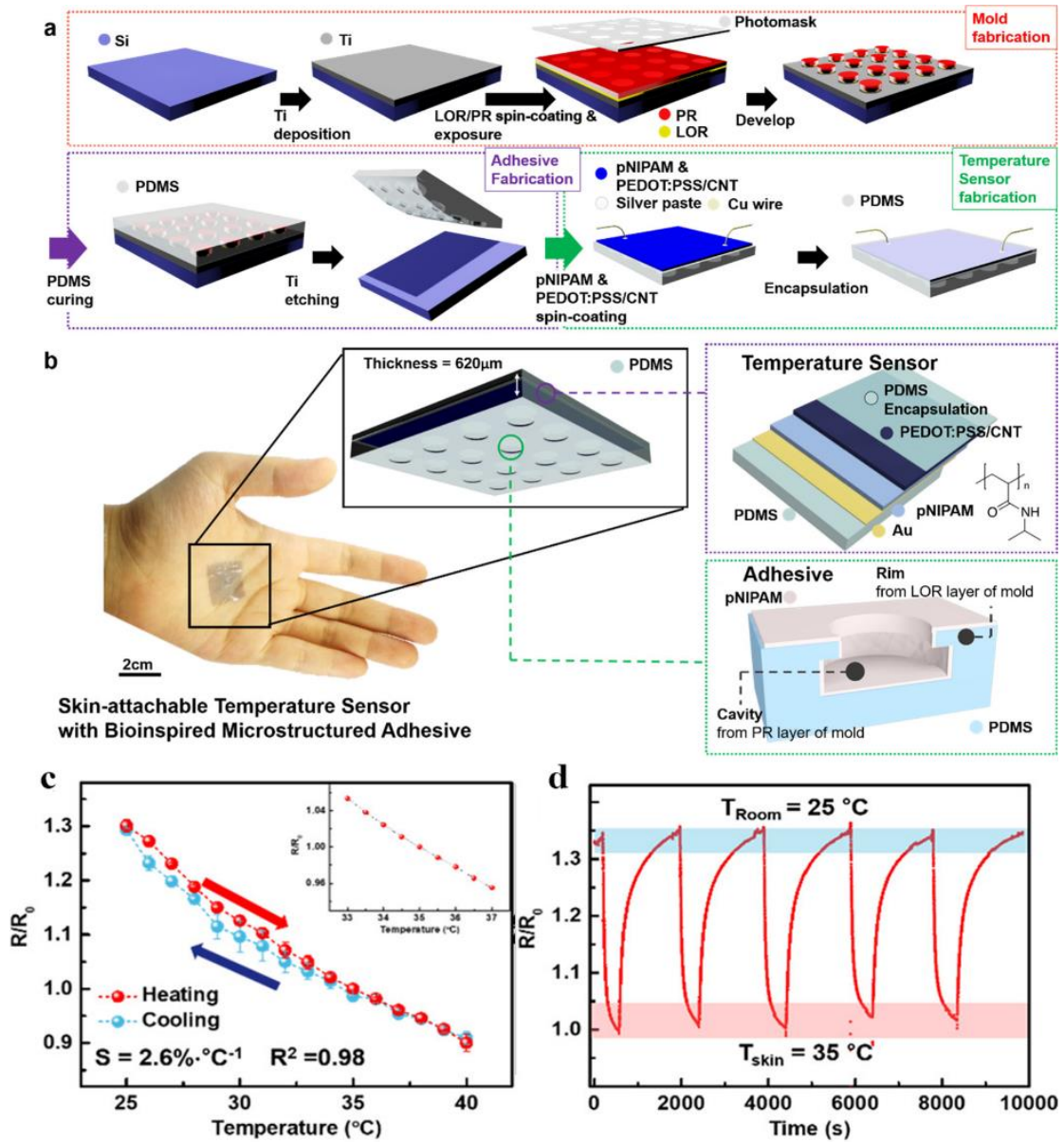

Fig. 4 (a-b) Schematic diagrams showing the fabrication of a temperature sensing layer composed of a composite of pNI-PAMhydrogel, poly(3,4-ethylenedioxythiophene) polystyrene sulfonate, and CNTs and encapsulated it between two PDMS thin films to fabricate a temperature sensor. (c) Dependence of relative resistance of the resulting temperature sensor on temperature. (d) Cycled measurement of the relative resistance changes of the resulting temperature sensor between 25 and $35^{\circ} \mathrm{C}$. Reprinted with permission from Ref. 135. Copyright (2018) American Chemical Society.

(a)

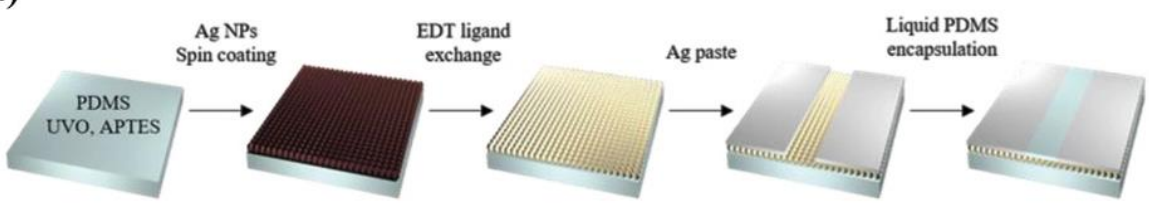

(b)

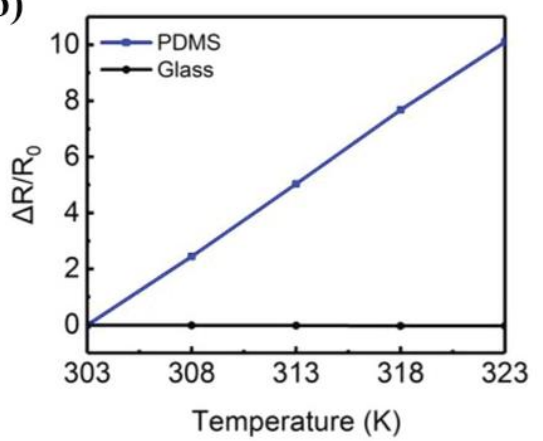

(c)

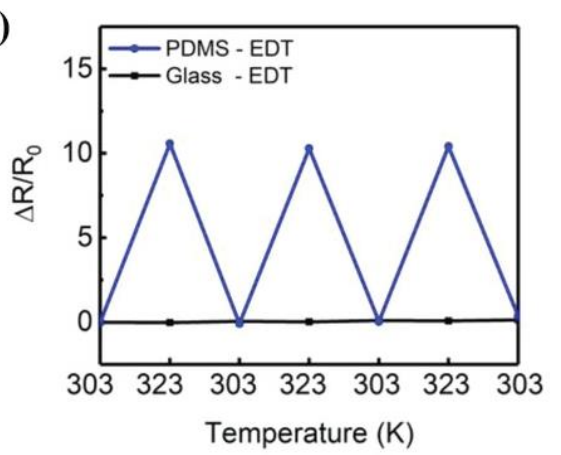

Fig. 5 (a) Schematic diagram showing the fabrication process of 1,2-ethanedithiol (EDT) ligand-treated Ag nanoparticle films on a PDMS substrate to design the temperature sensor. (b) Dependence of the relative resistance of Ag nanoparticle films treated with EDT on PDMS (blue) and glass (black) at 303, 308, 313, 318, and $323 \mathrm{~K}$. (c) Changes of the relative resistance of Ag nanoparticle films treated with EDT on PDMS (blue) and glass (black) when 303-323 K temperature cycles are applied. Reprinted with permission from Ref. 136. Copyright (2019) Wiley-VCH. 
temperature sensor, as shown in Fig. 4(a)-(b). This sensor shows a sensitivity of $2.6 \% \cdot{ }^{\circ} \mathrm{C}^{-1}$ between 25 and $40{ }^{\circ} \mathrm{C}$, which can even perceive a change in skin temperature of $0.5^{\circ} \mathrm{C}$ (Fig. $4(\mathrm{c})$ ). Moreover, it is observed that the sensor outputs a stable change in resistance during the repeated cycles in temperature between 25 and $35{ }^{\circ} \mathrm{C}$ (Fig. 4(d)), indicating that it has good reproducibility and stability in temperature sensing. In addition, Bang et al. ${ }^{[136]}$ embedded a layer of organic ligandtreated $\mathrm{Ag}$ nanoparticle thin film between two PDMS substrates to design the highly-sensitive temperature sensor (Fig. 5(a)), which exhibited a high temperature coefficient of resistance up to $0.5 \mathrm{~K}^{-1}$. It is observed that the relative resistance of the resulting temperature sensor is linearly increased as the temperature is increased from 303 to $323 \mathrm{~K}$. When the temperature changes from 303 to $323 \mathrm{~K}$, it is noted that the resistance is greatly increased ca. 10 times, as shown in Fig. 5(b). This sensor also exhibits excellent stability and reliability when 303-323 K temperature cycles are applied (Fig. 5(c)). Moreover, Bae et al. ${ }^{[132]}$ used the reduced graphene oxide (RGO) with an optimized degree of reduction as the thermistor to be embedded inside the parylene substrate,

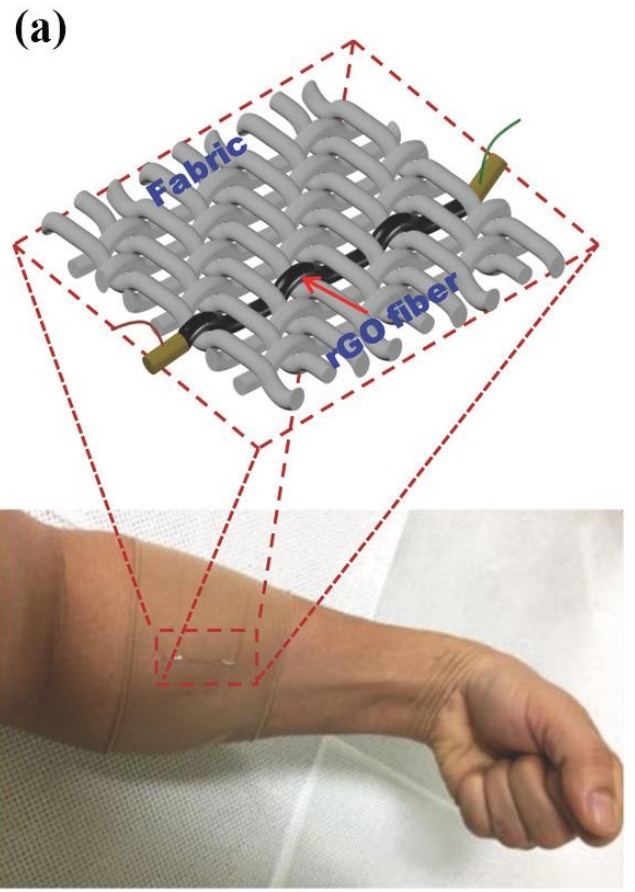

which exhibited a linear and reproducible temperature coefficient of resistance of $0.83 \% \mathrm{~K}^{-1}$ in the temperature range $22-70{ }^{\circ} \mathrm{C}$.

Beside layer-based temperature sensors, fiber-based temperature sensors were also recently developed to integrate on textiles or clothing systems to design wearable temperature sensors. For instance, Trunget al ${ }^{[137]}$ used the wet- spinning method and in-situ reduction process to fabricate the freestanding single RGO fiber with a diameter of $\sim 40 \mathrm{um}$. The RGO fiber served as a temperature sensor and was directly knitted on fabric to fabricate a wearable temperature sensor. This sensor can be worn on an arm to monitor body temperature, as shown in Fig. 6(a). From Fig. 6(b), the fabric containing the RGO fiber-based temperature sensor can be used to monitor the human body temperature. It is calculated that the response time and recovery time of the RGO fiberbased temperature sensor are 7 and $20 \mathrm{~s}$, respectively. Moreover, Fig. 6(c) shows that the sensor exhibits good repeatability and stability during the cycles of touchingremoval of a human finger.

(b)
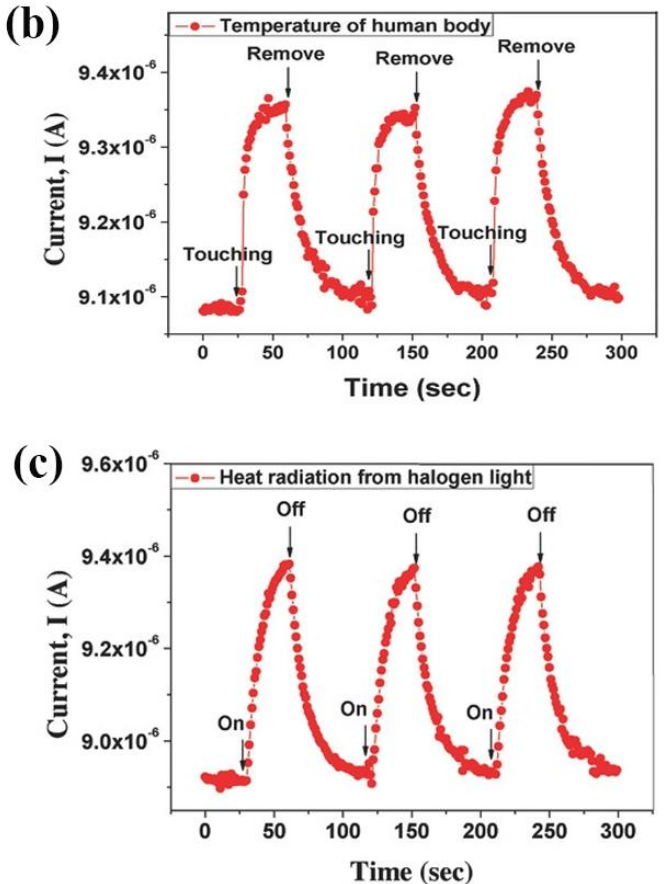

Fig. 6 (a) Schematic diagrams for the directly knitting a freestanding single RGO fiber into fabric and wearing on an arm; (b) Timedependent response current of the temperature sensor when touch a human body and remove from the body. The extracted values of response time ( $7 \mathrm{~s}$ ) and recovery time (20 s), respectively; (c) Time-dependent response current of fabricated temperature sensor under three cycles of exposure to human body. Reprinted with permission from Ref. 137. Copyright (2018) Wiley-VCH.

\section{Current challenges of CPCs-based temperature sensor}

Up to now, some high-performance CPCs-based temperature sensors were prepared and exhibited outstanding flexibility, high sensitivity and good stability. Despite great progress on thermo-electrical properties of CPCs has been achieved in recent years, there are still many challenges for the CPCs- based temperature sensors to meet practical applications. First of all, it is a tremendous problem to design a CPCs-based temperature sensor without sensitivity to strain, pressure, solvents or other external stimuli. In application, the responses of temperature sensors to other external stimuli will no doubt affect the temperature detection and display. Secondly, a 
linear and reproducible temperature coefficient of resistance is necessary for CPCs-based temperature sensors. Nonlinear and irreversible resistance responses seriously hinder the application of most CPCs-based temperature sensors. Finally, the self-healing performance of CPCs-based temperature sensors is also worthy of exploration, which is conducive to improve the durability of CPCs. However, it is still a challenge to endow CPCs-based temperature sensors with excellent selfhealing performance for the moment.

\section{Conclusions and outlook}

Conductive polymer composites (CPCs) are composed of conductive fillers or components and host polymer. These CPCs will exhibit thermo-electrical behavior under the stimulus of temperature. Utilizing this feature, CPCs can be designed into temperature sensors applied in various fields. For the classic filling-type CPCs, the conductive fillers are randomly distributed in the polymer matrix. Therefore, both PTC and NTC effects are observed upon heating. This hinders the filling-type CPCs in practical applications as temperature sensors. Some more complex structures, such as segregated structure and foamed structure, are utilized to fabricate fillingtype CPCs with only PTC or NTC effect upon heating. Attributed to the structural design, these CPCs can be designed into temperature sensors.

Beside the filling-type CPCs-based temperature sensors, it is another strategy to embed a layer of conductive components (e.g. conductive nanoparticles, nanofibers, and conductive polymers) inside the flexible polymer substrate, which can provide more sensitive and stable temperature sensing function. Moreover, the conductive components are also made into fibers and knitted on fabric to fabricate a wearable temperature sensor.

After years of development, different types of CPCs-based temperature sensors were developed. Both the sensitivity and stability of the resulting sensors have been significantly improved. Attributed to the outstanding flexibility of CPCsbased temperature sensors, their major application scenarios are the electronic skins (e-skins) and health monitoring, which need the CPCs-based temperature sensors to possess some characteristics, such as only responding to temperature, a linear and reproducible temperature coefficient of resistance, self-repairing performance, and so on. Therefore, in-depth exploration of thermo-electrical properties of $\mathrm{CPCs}$ is imperative to promote their practical application as temperature sensors.

\section{Acknowledgements}

This work was financially supported by Zhejiang National Science Fund for Distinguished Young Scholars (LR20E030003), the National Natural Science Foundation of China for General Program (21774126), and the start-up fund from Hangzhou Normal University.

\section{Conflict of Interest}

There are no conflicts to declare.

\section{Support information}

Not applicable

\section{References}

[1] J. Huang, Y. Zhu, W. Jiang, J. Yin, Q. Tang and X. Yang, ACS Appl. Mater. Interfaces, 2014, 6, 1754-1758, doi:10.1021/am404758d.

[2] X. Cui, J. Chen, Y. Zhu and W. Jiang, Chem. Eng. J., 2020, 382, 122823, doi: 10.1016/j.cej.2019.122823.

[3] D. Pan, X. Zhang, G. Yang, Y. Shang, F. Su, Q. Hu, R. R. Patil, H, Liu, C. Liu and Z. Guo, Ind. Eng. Chem. Res., 2020, 59, 2037120381, doi: 10.1021/acs.iecr.0c04510.

[4] J. Huang, J. Xu, Y. Sheng, Y. Zhu, W. Jiang, D. Xu, Q. Tang and X. Nie, Macromol. Mater. Eng., 2016, 301, 743-749, doi: 10.1002/mame.201600026.

[5] J. Chen, X. Cui, K. Sui, Y. Zhu and W. Jiang, Compos. Sci. Technol., 2017, 140, 99-105, doi: 10.1016/j.compscitech.2016.12.029.

[6] J. Chen, H. Li, Q. Yu, Y. Hu, X. Cui, Y. Zhu and W. Jiang, Compos. Sci. Technol., 2018, 168, 388-396, doi: 10.1016/j.compscitech.2018.10.025.

[7] S. Zheng, J. Deng, L. Yang, D. Ren, S. Huang, W. Yang, Z. Liu and M. Yang, Compos. Sci. Technol., 2014, 97, 34-40, doi: 10.1016/j.compscitech.2014.04.001.

[8] P. Zhan, W. Zhai, N. Wang, X. Wei, G. Zheng, K. Dai, C. Liu and C. Shen, Mater. Lett., 2019, 236, 60-63, doi: 10.1016/j.matlet.2018.10.068.

[9] M. H. Al-Saleh and U. Sundararaj, Compos. Part A., 2008, 39, 284-293, doi: 10.1016/j.compositesa.2007.10.010.

[10] L. Duan, M. Spoerk, T. Wieme, P. Cornillie, H. Xia, J. Zhang, L. Cardon and D. D'Hooge, Compos. Sci. Technol., 2019, 171, 78-85, doi: 10.1016/j.compscitech.2018.12.009.

[11] L. F. Ma, R. Y. Bao, S. L. Huang, Z. Y. Liu, W. Yang, B. H. Xie and M. B. Yang, J. Mater. Sci., 2013, 48, 4942-4951, doi: 10.1007/s10853-013-7275-z.

[12] Y. Qin, M. Qu, Y. Pan, C. Zhang and D. Schubert, Compos. Part A., 2020, 129, 105724, doi: 10.1016/j.compositesa.2019.105724.

[13] M. Qu, F. Nilsson and D. W. Schubert, Nanotechnology, 2019, 30, 245703, doi: 10.1088/1361-6528/ab0bec.

[14] X. Liu, C. Li, Y. Pan, D. W. Schubert and C. Liu, Compos. Part B., 2019, 164, 37-44, doi: 10.1016/j.compositesb.2018.11.054.

[15] Y. Pan, X. Liu, J. Kaschta, X. Hao, C. Liu and D. W. Schubert, Polymer, 2017, 113, 34-38, doi: 10.1016/j.polymer.2017.02.050.

[16] Y. Pan, X. Liu, X. Hao and D. W. Schubert, Phys. Chem. Chem. Phys., 2016, 18, 32125-32131, doi: 10.1039/C6CP06175C. [17] W. Thongruang, C. M. Balik and R. J. Spontak, J. Polym. Sci. Pol. Phys., 2002, 40, 1013-1025, doi: 10.1002/polb.10157.

[18] W. Thongruang, R. J. Spontak and C. M. Balik, Polymer, 2002, 43, 3717-3725, doi: 10.1016/S0032-3861(02)00180-5. 
[19] Z. Xu, N. Wang, N. Li, G. Zheng, K. Dai, C. Liu and C. Shen, Compos. Part B., 2016, 94, 45-51, doi: 10.1016/j.compositesb.2016.03.047.

[20] S. Wu, J. Zhang, R. B. Ladani, A. R. Ravindran, A. P. Mouritz, A. J. Kinloch and C. H. Wang, ACS Appl. Mater Interfaces, 2017, 9, 14207-14215, doi: 10.1021/acsami.7b00847. [21] F. Zhang, S. Wu, S. Peng and C. Wang, Compos. Sci. Technol., 2018, $\quad \mathbf{1 6 5}, \quad 131-139, \quad$ doi: 10.1016/j.compscitech.2018.06.019.

[22] Y. F. Fu, F. L. Yi, J. R. Liu, Y. Q. Li, Z. Y. Wang, G. Yang, P. Huang, N. Hu and S. Y. Fu, Compos. Sci. Technol., 2020, 186, 107910, doi: 10.1016/j.compscitech.2019.107910.

[23] M. Qu, F. Nilsson, Y. Qin, G. Yang, Y. Pan, X. Liu, G. Hernandez Rodriguez, J. Chen, C. Zhang and D. W. Schubert, Compos. Sci. Technol., 2017, 150, 24-31, doi: 10.1016/j.compscitech.2017.07.004.

[24] M. Qu and D. W. Schubert, Compos. Sci. Technol., 2016, 136, 111-118, doi: 10.1016/j.compscitech.2016.10.009.

[25] L. Cai, J. Li, P. Luan, H. Dong, D. Zhao, Q. Zhang, X. Zhang, M. Tu, Q. Zeng, W. Zhou and S. Xie, Adv. Funct. Mater., 2012, 22, 5238-5244, doi: 10.1002/adfm.201201013.

[26] D. W. Park, B. S. Kim, S. Park, W. J. Choi, C. S. Yang and J. O. Lee, J. Korean Phys. Soc., 2014, 64, 488-491, doi: 10.3938/jkps.64.488.

[27] Q. Cao and J. A. Rogers, Adv. Mater., 2009, 21, 29-53, doi: 10.1002/adma.200801995.

[28] B. Krause, V. Bezugly, V. Khavrus, L. Ye, G. Cuniberti and P. Pötschke, Energies, 2020, 13, 394, doi: 10.3390/en13020394.

[29] B. Krause, C. Barbier, K. Kunz and P. Pötschke, Polymer, 2018, 159, 75-85, doi: 10.1016/j.polymer.2018.11.010.

[30] J. Chen, X. Cui, Y. Zhu, W. Jiang and K. Sui, Carbon, 2017, 114, 441-448, doi: 10.1016/j.carbon.2016.12.048.

[31] J. Huang, C. Mao, Y. Zhu, W. Jiang and X. Yang, Carbon, 2014, 73, 267-274, doi: 10.1016/j.carbon.2014.02.063.

[32] J. Huang, Y. Zhu, W. Jiang and Q. Tang, Compos. Part A., 2015, 69, 240-246, doi: 10.1016/j.compositesa.2014.11.023.

[33] H. Zhang, J. Chen, X. Cui, Y. Hu, L. Lei, Y. Zhu and W. Jiang, Compos. Sci. Technol., 2018, 167, 522-528, doi: 10.1016/j.compscitech.2018.08.048.

[34] X. J. Zha, T. Li, R. Y. Bao, L. Bai, Z. Y. Liu, W. Yang and M. B. Yang, Compos. Sci. Technol., 2017, 139, 17-25, doi: 10.1016/j.compscitech.2016.12.011.

[35] X. Zhao, H. Wang, Z. Fu and Y. Li, ACS Appl. Mater. Interfaces, 2018, 10, 8411-8416, doi: 10.1021/acsami.8b01704.

[36] T. Gao, Y. Y. Li, R. Y. Bao, Z. Y. Liu, B. H. Xie, M. B. Yang and W. Yang, Compos. Sci. Technol., 2017, 152, 111-119, doi: 10.1016/j.compscitech.2017.09.014.

[37] S. H. Ryu, H. B. Cho, S. Kim, Y. T. Kwon, J. Lee, K. R. Park and Y. H. Choa, Compos. Sci. Technol., 2018, 165, 1-8, doi: 10.1016/j.compscitech.2018.06.005.

[38] F. Mai, H. Deng, W. Tu, S. Chankajorn, Q. Fu, E. Bilotti and T. Peijs, Macromol. Mater. Eng., 2015, 300, 1257-1267, doi: 10.1002/mame.201500163.
[39] F. Faraguna, P. Pötschke and J. Pionteck, Polymer, 2017, 132, 325-341, doi: 10.1016/j.polymer.2017.11.014.

[40] C. Mao, J. Huang, Y. Zhu, W. Jiang, Q. Tang and X. Ma, J. Phys. Chem. Lett., 2013, 4, 43-47, doi: 10.1021/jz301811b.

[41] C. Gao, S. Zhang, F. Wang, B. Wen, C. Han, Y. Ding and M. Yang, ACS Appl. Mater. Interfaces, 2014, 6, 12252-12260, doi: 10.1021/am501843s.

[42] Y. Tan, L. Fang, J. Xiao, Y. Song and Q. Zheng, Polym. Chem., 2013, 4, 2939-2944, doi: 10.1039/c3py00164d.

[43] Y. Yang, Y. F. Yang, L. Q. Tao, Y. Pang, H. Tian, Z. Y. Ju, X. M. Wu and T. L. Ren, Nanoscale, 2018, 10, 11524-11530, doi: 10.1039/c8nr02652a.

[44] C. F. Cao, G. D. Zhang, L. Zhao, L. X. Gong, J. F. Gao, J. X. Jiang, L. C. Tang and Y. W. Mai, Compos. Sci. Technol., 2019, 171, 162-170, doi: 10.1016/j.compscitech.2018.12.014.

[45] L. Z. Guan, L. Zhao, Y. J. Wan and L. C. Tang, Nanoscale, 2018, 10, 14788-14811, doi: 10.1039/c8nr03044h.

[46] F. Qiang, L. L. Hu, L. X. Gong, L. Zhao, S. N. Li and L. C. Tang, Chem. Eng. J., 2018, 334, 2154-2166, doi: 10.1016/j.cej.2017.11.054.

[47] P. Pokharel, D. Xiao, F. Erogbogbo, O. Keles and D. S. Lee, Compos. Part B Eng., 2019, 161, 169-182, doi: 10.1016/j.compositesb.2018.10.057.

[48] Z. Ma, A. Wei, J. Ma, L. Shao, H. Jiang, D. Dong, Z. Ji, Q. Wang and S. Kang, Nanoscale, 2018, 10, 7116-7126, doi: $10.1039 / \mathrm{c} 8 \mathrm{nr} 00004 \mathrm{~b}$.

[49] N. Bagotia, V. Choudhary and D. K. Sharma, Compos. Part B., 2019, 159, 378-388, doi: 10.1016/j.compositesb.2018.10.009. [50] L. Chen, G. Chen and L. Lu, Adv. Funct. Mater, 2007, 17, 898-904, doi: 10.1002/adfm.200600519.

[51] A. Fina, Z. Han, G. Saracco, U. Gross and M. Mainil, Polym. Adv. Technol., 2012, 23, 1572-1579, doi: 10.1002/pat.3031.

[52] G. Wang, G. Zhao, S. Wang, L. Zhang and C. B. Park, J. Mater. Chem. C, 2018, 6, 6847-6859, doi: 10.1039/c8tc01326h.

[53] B. Wen and X. Zheng, Compos. Sci. Technol., 2019, 174, 6875, doi: 10.1016/j.compscitech.2019.02.017.

[54] J. Wu, H. Wang, Z. Su, M. Zhang, X. Hu, Y. Wang, Z. Wang, B. Zhong, W. Zhou, J. Liu and S. G. Xing, ACS Appl. Mater. Interfaces, 2017, 9, 38745-38754, doi: 10.1021/acsami.7b10316. [55] S. Kuester, C. Merlini, G. M. O. Barra, J. C. Ferreira, A. Lucas, A. C. de Souza and B. G. Soares, Compos. Part B., 2016, 84, 236-247, doi: 10.1016/j.compositesb.2015.09.001.

[56] J. Lee, S. Kim, J. Lee, D. Yang, B. Park, S. Ryu and I. Park, Nanoscale, 2014, 6, 11932-11939, doi: 10.1039/c4nr03295k.

[57] S. H. Min, G. Y. Lee and S. H. Ahn, Compos. Part B., 2019, 161, 395-401, doi: 10.1016/j.compositesb.2018.12.107.

[58] J. Y. Kim and K. S. Jang, J. Nanomater, 2018, 2018, 4580921, doi: 10.1155/2018/4580921.

[59] S. X. Li, H. Xia, Y. Xu, C. Lv, G. Wang, Y. Z. Dai and H. B. Sun, Nanoscale, 2019, 11, 4925-4932, doi: 10.1039/c9nr00595a.

[60] M. Amjadi, A. Pichitpajongkit, S. Lee, S. Ryu and I. Park, ACS Nano, 2014, 8, 5154-5163, doi: 10.1021/nn501204t.

[61] M. Yang, S. W. Kim, S. Zhang, D. Y. Park, C. W. Lee, Y. H. 
Ko, H. Yang, Y. Xiao, G. Chen and M. Li, J. Mater. Chem. C, 2018, 6, 7207-7218, doi: 10.1039/c8tc01691g.

[62] M. Chen, S. Duan, L. Zhang, Z. Wang and C. Li, Chem. Commun., 2015, 51, 3169-3172, doi: 10.1039/c4cc09367d.

[63] G. Li, Z. Qiu, Y. Wang, Y. Hong, Y. Wan, J. Zhang, J. Yang, Z. Wu, W. Hong and C. F. Guo, ACS Appl. Mater. Interfaces, 2019, 11, 10373-10379, doi: 10.1021/acsami.8b20255.

[64] Y. Liu and M. Liu, Compos. Sci. Technol., 2017, 143, 56-66, doi: 10.1016/j.compscitech.2017.03.001.

[65] Z. Zhou, X. Zhang, X. Wu and C. Lu, Compos. Sci.Technol., 2016, 125, 1-8, doi:10.1016/j.compscitech.2016.01.016.

[66] M. Tian, Y. Wang, L. Qu, S. Zhu, G. Han, X. Zhang, Q. Zhou, M. Du and S. Chi, Synth. Met., 2016, 219, 11-19, doi: 10.1016/j.synthmet.2016.05.005.

[67] S. Zheng, X. Wu, Y. Huang, Z. Xu, W. Yang, Z. Liu, S. Huang, B. Xie and M. Yang, Compos. Part A., 2019, 121, 510-516, doi: 10.1016/j.compositesa.2019.04.014.

[68] J. C. Huang, Adv. Polym. Tech., 2002, 21, 299-313, doi: $10.1002 /$ adv. 10025 .

[69] N. D. Alexopoulos, C. Bartholome, P. Poulin and Z. MarioliRiga, Compos. Sci. Technol., 2010, 70, 260-271, doi: 10.1016/j.compscitech.2009.10.017.

[70] V. Eswaraiah, K. Balasubramaniam and S. Ramaprabhu, $J$. Mater. Chem., 2011, 21, 12626-12628, doi: 10.1039/c1jm12302e. [71] N. Lu, C. Lu, S. Yang and J. Rogers, Adv. Funct. Mater, 2012, 22, 4044-4050, doi: 10.1002/adfm.201200498.

[72] L. Lin, H. Deng, X. Gao, S. Zhang, E. Bilotti, T. Peijs and Q. Fu, Polym. Int., 2013, 62, 134-140, doi: 10.1002/pi.4291.

[73] L. Lin, S. Liu, Q. Zhang, X. Li, M. Ji, H. Deng and Q. Fu, ACS Appl. Mater. Interfaces, 2013, 5, 5815-5824, doi: 10.1021/am401402x.

[74] J. Chen, Y. Zhu and W. Jiang, Compos. Sci. Technol., 2020, 186, 107938, doi: 10.1016/j.compscitech.2019.107938.

[75] J. H. Pu, X. J. Zha, M. Zhao, S. Li, R. Y. Bao, Z. Y. Liu, B. H. Xie, M. B. Yang, Z. Guo and W. Yang, Nanoscale, 2018, 10, 2191-2198, doi: 10.1039/c7nr08077h.

[76] J. Ma, P. Wang, H. Chen, S. Bao, W. Chen and H. Lu, ACS Appl. Mater. Interfaces, 2019, 11, 8527-8536, doi: 10.1021/acsami.8b20902.

[77] T. Huang, P. He, R. Wang, S. Yang, J. Sun, X. Xie and G. Ding, Adv. Funct. Mater., 2019, 29, 1903732, doi: 10.1002/adfm.201903732.

[78] S. Liu, Y. Lin, Y. Wei, S. Chen, J. Zhu and L. Liu, Compos. Sci. Technol., 2017, 146, 110-118, doi 10.1016/j.compscitech.2017.03.044.

[79] J. Zhou, X. Xu, Y. Xin and G. Lubineau, Adv. Funct. Mater. 2018, 28, 1705591, doi: 10.1002/adfm.201705591.

[80] X. Chen, H. Liu, Y. Zheng, Y. Zhai, X. Liu, C. Liu, L. Mi, Z. Guo and C. Shen, ACS Appl. Mater. Interfaces, 2019, 11, 42594 42606, doi: 10.1021/acsami.9b14688.

[81] Y. Wan, Z. Qiu, Y. Hong, Y. Wang, J. Zhang, Q. Liu, Z. Wu and C. F. Guo, Adv. Electron. Mater., 2018, 4, 1700586, doi: 10.1002/aelm.201700586.
[82] X. You, J. He, N. Nan, X. Sun, K. Qi, Y. Zhou, W. Shao, F. Liu and S. Cui, J. Mater. Chem. C, 2018, 6, 12981-12991, doi: 10.1039/C8TC03631D.

[83] J. Lee, H. Kwon, J. Seo, S. Shin, J. H. Koo, C. Pang, S. Son, J. H. Kim, Y. H. Jang, D. E. Kim and T. Lee, Adv. Mater., 2015, 27, 2433-2439, doi: 10.1002/adma.201500009.

[84] Y. Zhang, Y. Fang, J. Li, Q. Zhou, Y. Xiao, K. Zhang, B. Luo, J. Zhou and B. Hu, ACS Appl. Mater. Interfaces, 2017, 9, 3749337500, doi: 10.1021/acsami.7b13016.

[85] M. Wang, K. Zhang, X. X. Dai, Y. Li, J. Guo, H. Liu, G. H. Li, Y. J. Tan, J. B. Zeng and Z. Guo, Nanoscale, 2017, 9, $11017-$ 11026, doi: 10.1039/c7nr02322g.

[86] L. Zhao, F. Qiang, S. Dai, S. Shen, Y. Huang, N. J. Huang, G. Zhang, L. Z. Guan, J. Gao, Y. Song and L. C. Tang, Nanoscale, 2019, 11, 10229-10238, doi: 10.1039/c9nr02672j.

[87] Y. Lu, M. Tian, X. Sun, N. Pan, F. Chen, S. Zhu, X. Zhang and S. Chen, Compos. Part A., 2019, 117, 202-210, doi: 10.1016/j.compositesa.2018.11.023.

[88] M. Chen, K. Li, G. Cheng, K. He, W. Li, D. Zhang, W. Li, Y. Feng, L. Wei, W. Li, G. Zhong and C. Yang, ACS Appl. Mater. Interfaces, 2019, 11, 2551-2558, doi: 10.1021/acsami.8b20284.

[89] G. Yu, J. Hu, J. Tan, Y. Gao, Y. Lu and F. Xuan, Nanotechnology, 2018, 29, 115502, doi: 10.1088/1361$6528 /$ aaa855

[90] X. Jiang, Z. Ren, Y. Fu, Y. Liu, R. Zou, G. Ji, H. Ning, Y. Li, J. Wen, H. J. Qi, C. Xu, S. Fu, J. Qiu and N. Hu, ACS Appl. Mater. Interfaces, 2019, 11, 37051-37059, doi: 10.1021/acsami.9b11596. [91] Y. Ding, T. Xu, O. Onyilagha, H. Fong and Z. Zhu, ACS Appl. Mater. Interfaces, 2019, 11, 6685-6704, doi: 10.1021/acsami.8b20929.

[92] N. Koratkar, A. Modi, E. Lass and P. Ajayan, J. Nanosci. Nanotechno., 2004, 4, 744-748, doi: 10.1166/jnn.2004.109.

[93] Y. L. Hou, P. Zhang and M. M. Xie, J. Appl. Polym. Sci., 2017, 134, 44876, doi: 10.1002/app.44876.

[94] P. Zhang and B. B. Wang, J. Appl. Polym. Sci., 2018, 135, 46453, doi: 10.1002/app.46453.

[95] S. Zhao, G. Li, H. Liu, K. Dai, G. Zheng, X. Yan, C. Liu, J. Chen, C. Shen and Z. Guo, Adv. Mater. Interfaces, 2017, 4, 1700265, doi: 10.1002/admi.201700265.

[96] H. Z. Zou, X. Zhang, S. D. Zheng, W. Yang, Z. Y. Liu, M. B. Yang and J. M. Feng, Acta Polym. Sin., 2017, 1215-1219, doi: 10.11777/j.issn1000-3304.2017.17090.

[97] P. Zhang, Y. Hou and B. Wang, Mater. Res. Express, 2018, 6, 035702, doi: 10.1088/2053-1591/aaf589.

[98] M. Yurddaskal, M. Erol and E. Celik, J. Mater. Sci-Mater. El., 2017, 28, 9514-9518, doi: 10.1007/s10854-017-6695-y.

[99] D. Pan, F. Su, H. Liu, Y. Ma, R. Das, Q. Hu, C. Liu and Z. Guo, Chem. Rec., 2020, 20, 1314-1337, doi: 10.1002/tcr.202000079.

[100] G. Rosace, V. Trovato, C. Colleoni, M. Caldara, V. Re, M. Brucale, E. Piperopoulos, E. Mastronardo, C. Milone, G. De Luca and M. R. Plutino, Sens. Actuators, B, 2017, 252, 428-439, doi: 10.1016/j.snb.2017.05.175. 
[101] Z. Wang, W. Gao, Q. Zhang, K. Zheng, J. Xu, W. Xu, E. Shang, J. Jiang, J. Zhang and Y. Liu, ACS Appl. Mater. Interfaces, 2019, 11, 1344-1352, doi: 10.1021/acsami.8b16139.

[102] H. Xu, Y. Li, N. J. Huang, Z. R. Yu, P. H. Wang, Z. H. Zhang, Q. Q. Xia, L. X. Gong, S. N. Li, L. Zhao, G. D. Zhang and L. C. Tang, J. Hazard. Mater, 2019, 363, 286-294, doi: 10.1016/j.jhazmat.2018.09.082.

[103] F. Jasmi, N. H. Azeman, A. A. A. Bakar, M. S. D. Zan, K. H. Badri and M. S. Su'ait, IEEE Access, 2018, 6, 47355-47363, doi: 10.1109/ACCESS.2018.2867220.

[104] X. Zhang, S. Zheng, H. Zou, X. Zheng, Z. Liu, W. Yang and M. Yang, Compos. Part A Appl. S., 2017, 94, 21-31, doi: 10.1016/j.compositesa.2016.12.001.

[105] X. M. Dong, R. W. Fu, M. Q. Zhang, B. Zhang and M. Z. Rong, Carbon, 2004, 42, 2551-2559, doi: 10.1016/j.carbon.2004.05.034.

[106] J. F. Feller, H. Guezenoc, H. Bellegou and Y. Grohens, Macromol. Symp., 2005, 222, 273-280, doi:10.1002/masy.200550436.

[107] P. Pötschke, T. Andres, T. Villmow, S. Pegel, H. Bruenig, K. Kobashi, D. Fischer and L. Haeussler, Compos. Sci. Technol., 2010, 70, 343-349, doi: 10.1016/j.compscitech.2009.11.005.

[108] P. Pötschke, K. Kobashi, T. Villmow, T. Andres, M. C. Paiva and J. A. Covas, Compos. Sci. Technol., 2011, 71, 1451-1460, doi: 10.1016/j.compscitech.2011.05.019.

[109] T. Villmow, S. Pegel, A. John, R. Rentenberger and P. Pötschke, Mater. Today, 2011, 14, 340-345, doi: 10.1016/S13697021(11)70164-X.

[110] T. Villmow, S. Pegel, P. Pötschke and G. Heinrich, Polymer, 2011, 52, 2276-2285, doi: 10.1016/j.polymer.2011.03.029.

[111] R. Rentenberger, A. Cayla, T. Villmow, D. Jehnichen, C. Campagne, M. Rochery, E. Devaux and P. Pötschke, Sensor Actuat. B-Chem., 2011, 160, 22-31, doi: 10.1016/j.snb.2011.07.004.

[112] D. Ponnamma, K. T. Varughese, M. A. A. Al-Maadeed and S. Thomas, Polym. Int., 2017, 66, 931-938, doi: 10.1002/pi.5341. [113] B. Dong, L. Zhang and Y. Wu, J. Mater. Sci., 2016, 51, 10561-10573, doi: 10.1007/s10853-016-0276-y.

[114] X. Zhou, L. Zhu, L. Fan, H. Deng and Q. Fu, ACS Appl. Mater. Interfaces, 2018, 10, 31655-31663, doi: 10.1021/acsami.8b11766.

[115] H. Deng, L. Lin, M. Ji, S. Zhang, M. Yang and Q. Fu, Prog. Polym. Sci., 2014, 39, 627-655, doi: 10.1016/j.progpolymsci.2013.07.007.

[116] H. Pang, L. Xu, D. X. Yan and Z. M. Li, Prog. Polym. Sci., 2014, 39, 1908-1933, doi: 10.1016/j.progpolymsci.2014.07.007. [117] L. Xie and Y. Zhu, Polym. Compos., 2017, 39, 2985-2996, doi: $10.1002 /$ pc. 24345 .

[118] J. W. Chen, Q. L. Yu, X. H. Cui, M. Y. Dong, J. X. Zhang, C. Wang, J. C. Fan, Y. T. Zhu and Z. H. Guo, J. Mater. Chem. C, 2019, 7, 11710-11730, doi: 10.1039/c9tc03655e.

[119] J. Chen, Y. Zhu, J. Huang, J. Zhang, D. Pan, J. Zhou, J. E. Ryu, A. Umar and Z. Guo, Polym. Rev., 2020, doi:
10.1080/15583724.2020.1734818.

[120] H. Liu, Q. Li, S. Zhang, R. Yin, X. Liu, Y. He, K. Dai, C. Shan, J. Guo, C. Liu, C. Shen, X. Wang, N. Wang, Z. Wang, R. Wei and Z. Guo, J. Mater. Chem. C, 2018, 6, 12121-12141, doi: 10.1039/C8TC04079F.

[121] A. Kono, K. Shimizu, H. Nakano, Y. Goto, Y. Kobayashi, T. Ougizawa and H. Horibe, Polymer, 2012, 53, 1760-1764, doi: 10.1016/j.polymer.2012.02.048.

[122] S. P. Bao, G. D. Liang and S. C. Tjong, Carbon, 2011, 49, 1758-1768, doi: 10.1016/j.carbon.2010.12.062.

[123] J. Jeon, H. B. R. Lee and Z. Bao, Adv. Mater, 2013, 25, 850-855, doi: 10.1002/adma.201204082.

[124] A. Rybak, G. Boiteux, F. Melis and G. Seytre, Compos. Sci. Technol, 2010, 70, 410-416, doi: 10.1016/j.compscitech.2009.11.019.

[125] K. Chu and S. H. Park, J. Ind. Eng. Chem., 2016, 35, $195-$ 198, doi: 10.1016/j.jiec.2015.12.033.

[126] Q. Zhang, L. Liu, C. Pan, D. Li and G. Gai, J. Mater. Chem. C, 2018, 6, 1746-1752, doi: 10.1039/c7tc05432g.

[127] Y. Qu, W. Zhang, K. Dai, G. Zheng, C. Liu, J. Chen and C. Shen, Mater. Lett., 2014, 132, 48-51, doi: 10.1016/j.matlet.2014.06.062.

[128] X. Zhang, X. Zheng, D. Ren, Z. Liu, W. Yang and M. Yang, Mater. Lett., 2016, 164, 587-590, doi: 10.1016/j.matlet.2015.11.077.

[129] Y. Wei, Z. Li, X. Liu, K. Dai, G. Zheng, C. Liu, J. Chen and C. Shen, Colloid Polym. Sci., 2014, 292, 2891-2898, doi: 10.1007/s00396-014-3334-5.

[130] X. Cui, J. Chen, Y. Zhu and W. Jiang, J. Mater. Chem. C, 2018, 6, 9354-9362, doi: 10.1039/c8tc02123f.

[131] C. Yan, J. Wang and P. S. Lee, ACS Nano, 2015, 9, 21302137, doi: 10.1021/nn507441c.

[132] G. Y. Bae, J. T. Han, G. Lee, S. Lee, S. W. Kim, S. Park, J. Kwon, S. Jung and K. Cho, Adv. Mater., 2018, 30, 1803388, doi: 10.1002/adma.201803388.

[133] S. Y. Hong, Y. H. Lee, H. Park, S. W. Jin, Y. R. Jeong, J. Yun, I. You, G. Zi and J. S. Ha, Adv. Mater, 2016, 28, 930-935, doi: 10.1002/adma.201504659.

[134] S. Zhao, D. Lou, P. Zhan, G. Li, K. Dai, J. Guo, G. Zheng, C. Liu, C. Shen and Z. Guo, J. Mater. Chem. C, 2017, 5, 82338242, doi: 10.1039/c7tc02472j.

[135] J. H. Oh, S. Y. Hong, H. Park, S. W. Jin, Y. R. Jeong, S. Y. Oh, J. Yun, H. Lee, J. W. Kim and J. S. Ha, ACS Appl. Mater. Interfaces, 2018, 10, 7263-7270, doi: 10.1021/acsami.7b17727.

[136] J. Bang, W. S. Lee, B. Park, H. Joh, H. K. Woo, S. Jeon, J. Ahn, C. Jeong, T. I. Kim and S. J. Oh, Adv. Funct. Mater, 2019, 29, 1903047, doi: 10.1002/adfm.201903047.

[137] T. Tran Quang, L. Hoang Sinh, D. Thi My Linh, S. Ju, S. Y. Park and N.E. Lee, Adv. Healthcare Mater.,2018, 7, 1800074, doi: 10.1002/adhm.201800074. 


\section{Author information}

\section{Dr Jianwen Chen}

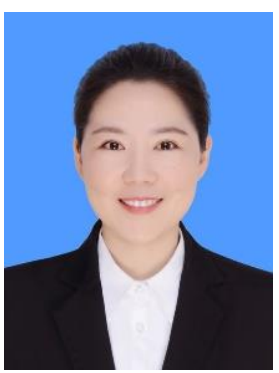

Dr Jianwen Chen received her PhD (2020) from State Key Laboratory of Polymer Physics and Chemistry, Changchun Institute of Applied Chemistry, Chinese Academy of Sciences (Supervisor: Prof. Yutian Zhu and Wei Jiang). During her PhD study, she worked as a joint PhD student with Prof. Yutian Zhu at Hangzhou Normal University. Her current research focuses on multifunctional sensing materials, especially conductive polymer composite based sensors.

\section{Dr Yutian Zhu}

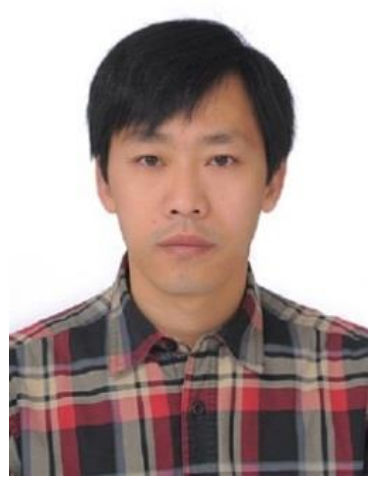

Dr Yutian Zhu is currently a professor at the College of Materials, Chemistry and Chemical Engineering, Hangzhou Normal University. Yutian Zhu obtained his bachelor degree in Applied Chemistry from Nanchang University in 2001 and his PhD in Polymer Chemistry and Physics from Changchun Institute of Applied Chemistry, Chinese Academy of Sciences in 2006. Then, he joined the Department of Chemical Engineering at $K U$ Leuven as a postdoctoral researcher. In 2008, he joined the Department of Chemistry at University of Memphis as a postdoctoral researcher. In 2010, he became an associate professor in State Key Laboratory of Polymer Physics and Chemistry, Changchun Institute of Applied Chemistry, Chinese Academy of Sciences. Then, he served as a full professor in Hangzhou Normal University since 2018. His current research is the multicomponent polymer nanocomposites and their applications in flexible sensors.

\section{Dr. Zhanhu Guo}

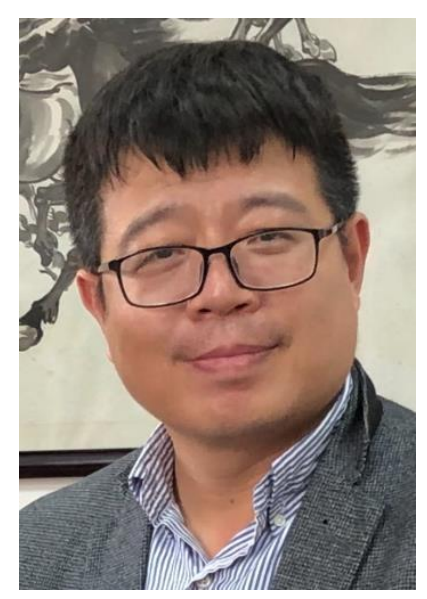

John Zhanhu Guo earned his Ph.D. degree in chemical engineering from Louisiana State University in 2005. He received his three-year postdoctoral training in mechanical and aerospace engineering at the University of California Los Angeles. He is a Professor in Chemical and Biomolecular Engineering directs the Integrated Composites Laboratory at The University of Tennessee, Knoxville. His current research interests are in the areas of optoelectronic, electric, and magnetic materials for solar cells, catalysis, sensing, and electronics.

\section{Dr. Sci. Albert G. Nasibulin}

Dr. Sci. Albert G. Nasibulin is a Professor at Skolkovo

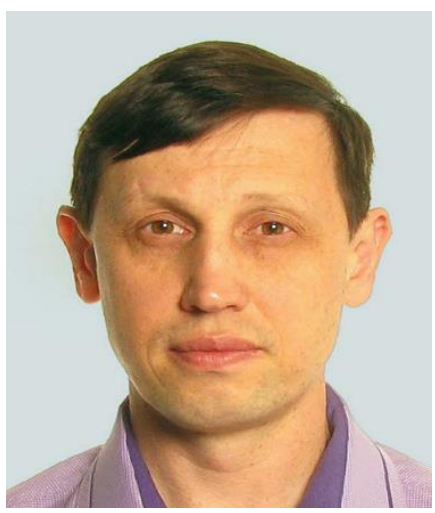
Institute of Science and Technology and an Adjunct Professor at the Department of Chemistry and Materials Science of Aalto University School of Chemical Engineering. He held a post of the Academy Research Fellow in Academy of Finland from 2006 to 2011. Since 2018 he is a Professor of the Russian Academy of Sciences. He got his PhD in Physical Chemistry (1996) at Kemerovo State University (Russia) and Doctor of Science (Habilitation, 2011) at Saint-Petersburg Technical State University (Russia). Prof. Albert Nasibulin has specialized in the aerosol synthesis of nanomaterials (nanoparticles, carbon nanotubes and tetrapods), investigations of their growth mechanisms and their applications.

Publisher's Note: Engineered Science Publisher remains neutral with regard to jurisdictional claims in published maps and institutional affiliations. 